\title{
Effect of Raja Yoga on Depression and Anxiety
}

\author{
Mahima Bhomavat ${ }^{1}$ \\ ${ }^{1}$ Post Graduate Student, Department of Psychology, L.J.N.J. Women's College, Mumbai \\ E-mail-mahimabhomavat@gmail.com
}

\section{ABSTRACT \\ Raja Yoga is a therapy which is comparatively new and widely} practiced. The present study aimed to investigate the effect of Raja Yoga for treating depression and anxiety. This was a quantitative research and data was collected using researcher administered questionnaire surveys. Participants comprised of 30 women diagnosed with depression and 30 women diagnosed with anxiety. Clinical questionnaires were distributed and pre and post study was established on the same population of home makers. A t-test as statistical measure was utilized in the study. Results indicate that Raja Yoga is effective in treating Depression and Anxiety $(p<0.05$ for anxiety and depression individually). The findings raised the possibility that Raja Yoga could be used as an effective treatment for Clinical disorders such as Depression and Anxiety.

Key words: anxiety, depression, Raja Yoga, effects.

\section{INTRODUCTION}

"Yoga" is a term which comes from the Sanskrit word "the yuj" or "to join" or "to direct one's attention". Yoga dates back to 3000 BC. The practice of yoga helps strength, endurance, compassion, flexibility, self -control and wellness [1]. The general nature of Yoga is defined to be the suppression and control of the five-fold mental activity which consists of true cognition (pramana), error (viparyaya), objectless ideation (vikalpa), cognition in dreamless sleep (nidra), and recollection (smrti). The purity and freedom of the self are obscured by the constant fluctuations of the mind with which the self identifies himself. This identification is due to the primal ignorance (avidya) which is a positive entity and manifests itself in the forms of perverted cognitions. Thus under the spell of avidya, the self regards what is non-eternal as eternal, impure as pure, pain as pleasure and non-self as self. It is due to its influence that the self feels his identity with the buddhi, develops attachment and hatred, and finally a will to live and irresistible dread for death [2].

Raja Yoga focuses upon controlling the mind and helps in purification of mind and teaches us to attain the state of divinity. It focuses on the harmonious development of the body, mind and soul. The other name of Raja Yoga is ashtanga yoga, which is Yoga of the eight limbs. Ashtanga Yoga was founded by Patanjali Maharshi, who was a physician along with a philosopher and a Yogi. Patanjali has described Raja Yoga where he has given eight limbs which consist of yama (self-restraint), niyama (religious 
observations), asana (posture), pranayama (restraint of breath), pratyahara(abstraction of senses), dharana (concentration), dhyana (meditation) and Samadhi (super-conscious state). Yama and Niyama work upon disciplining the senses and purifying the mind. Pranayama helps the mind to concentrate by making the mind firm and by removing the veil of Rajas (passion) and tamas (inertia) which covers up Sattva (purity) [3].

Raja Yoga teaches us to withdraw the mind from external forces and fix our attention at one point. By learning the right method of meditation and concentration, we can attain peace, perfection, freedom. By practicing Raja Yoga we learn to control the thoughts, discipline mind, to attain independence, immorality and freedom. Raja Yoga helps to get into the state of absolute peace where there is neither imagination nor thought. It helps in battling with stress, irritability and tension. Stress, irritability and tension are very prevalent in today's life. It teaches us to control faulty emotions and passions as well as lust for power, material greed, selfishness and passion for wealth. It helps increase concentration at work and removes fatigue and induces calmness as well as to resist temptations [3].

Anxiety and depression are among the most common conditions cited by those seeking treatment with complementary and alternative therapies, such as exercise, meditation, tai chi, qigong, and yoga. Several studies of exercise and yoga have demonstrated therapeutic effectiveness superior to no-activity controls and comparable with established depression and anxiety treatments. For anxiety disorders, exercise and yoga have also shown positive effects, but there are far less data on the effects of exercise on anxiety than for exercise on depression [4-5]. The aim of the research was to find out if Raja Yoga would be effective for the treatment of Depression and Anxiety. As women who are between 35 years and 50 years, experience isolation from the family, they develop depression and anxiety. As raja Yoga focuses on the mind and the inner self, it would be beneficial for the home makers to gain awareness about self and to maintain their self-confidence.

\section{METHODOLOGY}

The sample consisted of 60 females (homemakers) diagnosed with depression and anxiety (30 in each group). Sample was taken from Brahmakumari Centres from all over Mumbai City. The women were of age group 35- 50 years. The scales were distributed among the females and instructions were given and were asked to complete the inventory and were told that if anyone would have any doubts, it would be solved on one to one basis. From the date of filling the inventory after one month the inventories were again distributed among the same population of Females. In this one month the females used to practice Raja Yoga regularly.

\section{Scales used}

The scales Used to Measure the Depression and Anxiety were:

1. Becks Depression Inventory [6].

2. Becks Anxiety Inventory [7].

\section{Statistical analysis}

The data collected was subjected to appropriate statistical analysis and t-test was applied to check whether Raja Yoga was Effective in Depression and Anxiety. 


\section{RESULTS}

Table 1 displays the mean scores and standard deviations for the measure of pre-treatment depression and post-treatment depression. It was found that mean raw scores of pre- treatment depression and post treatment depression were 32.43 and 26.83 respectively while the standard deviations obtained were those of 6.59 and 6.02 respectively. To estimate a significant difference between pre treatment depression and post depression among depressive females, a t-test was computed. The $t$ value was found to be 3.39, which was statistically significant $(p<0.01)$. Table 2 displays the mean scores and standard deviations for the measure of pre-treatment anxiety and post-treatment anxiety. It was found that mean raw scores of pre- treatment anxiety and post treatment anxiety were 31.23 and 28.26 respectively while the standard deviations obtained were those of 4.43 and 3.93 respectively. To estimate a significant difference between pre treatment anxiety and post anxiety among anxious females, a ttest was computed. The $t$ value was found to be 2.34 , which was statistically significant $(p=0.02)$.

\section{DISCUSSION}

The main goal of the research was to establish whether Raja Yoga is effective in treating Depression and anxiety among women who are housewives. There was substantial difference in the pre-study and the post - study of depression and anxiety. The study proved that Raja Yoga would be effective in treating Depression among women who are home makers. Depression and Anxiety being the leading problems for a home maker, Raja Yoga could be an effective method of treatment for Depression and Anxiety. Researchers conducted a pilot study to investigate the effects of meditation with yoga among 46 individuals with long term depressive disorder and found that there was not much of a difference in the depressive patients but it displayed a higher significance for treating low to high level depression [8]. Others in their review found encouraging results in the treatment of anxiety and depression through Yoga [910]. The results of this study could be utilized as a para-medical treatment for clinical disorders such as depression and anxiety.

Table 1: Comparative Analysis of Mean and SD of Pre-Treatment and Post-Treatment of Depression

\begin{tabular}{|lccc|}
\hline DEPRESSION & & & \\
& MEAN & SD & \\
\hline PRE TREATMENT & 32.43 & 6.59 & $3.39 * *$ \\
\hline POST TREATMENT & 26.83 & 6.02 & \\
\hline
\end{tabular}

Significant at $0.05^{* *}$ 
Table 2: Comparative Analysis of Mean and SD of Pre-Treatment and Post-Treatment of Anxiety

\begin{tabular}{|lccc|}
\hline ANXIETY & & & \\
& MEAN & SD & \\
\hline PRE TREATMENT & 31.23 & 4.43 & $2.34 * *$ \\
\hline POST TREATMENT & 28.26 & 3.93 & \\
\hline
\end{tabular}

\section{REFERENCES}

1. Woodyard C. Exploring the therapeutic effects of yoga and its ability to increase quality of life, Int J Yoga 2011;4(2):49-54.

2. Radhakrishnan S. History of Philosophy Eastern and Western. Delhi Book Depot ; 1952.

3. Sivananda S. Raja Yoga (Vol. 4). Divine Life Society, Fremantle Branch ; 1986.

4. Saeed SA, Antonacci DJ, Bloch RM. Exercise, yoga, and meditation for depressive and anxiety disorders. Am Fam Physician 2010;81(8):981-6.

5. Brown RP, Gerbarg PL. Sudarshan Kriya Yogic Breathing in the Treatment of Stress, Anxiety, and Depression: Part I-Neurophysiologic Model. J Altern Compl Med 2005;11(1):189-201.

6. Beck AT, Ward $\mathrm{CH}$, Mendelson M, Mock J, Erbaugh J. An inventory for measuring depression. Arch Gen Psychiatry 1961;4(6):561-71.

7. Beck AT, Epstein N, Brown G, Steer RA. An inventory for measuring clinical anxiety: psychometric properties. J Consult Clin Psychol 1988;56:893-7.

8. Butler LD, Waelde LC, Hastings TA, Chen XH, Symons B, Marshall J, Spiegel D. Meditation with yoga, group therapy with hypnosis, and psychoeducation for long-term depressed mood: a randomized pilot trial. J Clin Psychol 2008;64(7):806-20.

9. Kirkwood G, Rampes H, Tuffrey V, Richardson J, Pilkington K. Yoga for anxiety: a systematic review of the research evidence. Br J Sports Med 2005;39(12):88491.

10. Pilkington K, Kirkwood $G$, Rampes $H$, Richardson J. Yoga for depression: the research evidence. J Affect Disord 2005;89(1-3):13-24.

Acknowledgements - Dr. Sheba Kumar Singh for her constant guidance and support.

Conflict of Interest - Nil

Funding - Nil. 